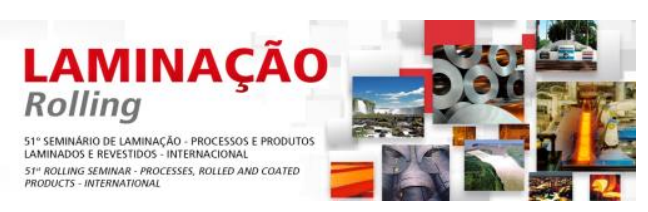

\title{
EFEITO DA ADIÇÃO DE BORO NO AÇO BIFÁSICO DP980 NA ARCELORMITTAL BRASIL*
}

\author{
Juliovany Drumond 1 \\ Flávio José Saraiva Rodrigues ${ }^{2}$ \\ Gabriel Godinho Alves ${ }^{2}$ \\ Gladistone de Souza Guerra² \\ Fabrício Moreira Cerqueira ${ }^{3}$
}

\begin{abstract}
Resumo
Este trabalho apresenta os resultados da produção do aço bifásico DP980 galvanizado a quente na ArcelorMittal Brasil, com foco no atendimento às propriedades mecânicas e microestruturais. Foram analisadas bobinas produzidas industrialmente de um aço bifásico baixo carbono com e sem adição de boro, e também amostras para simulação de recozimento. A análise foi baseada nas propriedades obtidas no ensaio de tração e também na microestrutura. Foi observado que o aço com adição de boro apresentou propriedades mecânicas mais elevadas que o aço sem a adição deste elemento, e este aumento está diretamente relacionado à maior fração volumétrica de martensita encontrada neste aço. Este fato está ligado à segregação do boro nas interfaces ferrita / austenita durante o recozimento intercrítico, evitando assim a nucleação e crescimento da "nova" ferrita, com um consequente enriquecimento de carbono na austenita. Esta austenita mais enriquecida de carbono gera uma maior quantidade de martensita na microestrutura final. Diante disso, o aço DP980 produzido industrialmente com adição de boro apresentou melhores propriedades mecânicas e microestruturais, sendo compatível com os requisitos demandados atualmente pela indústria automotiva, quando galvanizado a quente nas condições de processo estabelecidas neste estudo.
\end{abstract}

Palavras-chave: Bifásicos; Boro; Martensita.

\section{EFFECT OF BORON ADDITION ON DP980 STEEL AT ARCELORMITTAL BRAZIL Abstract}

This study shows the details of the production of DP980 steel at ArcelorMittal Brazil, with focus on mechanical properties and microstructure. Were studied coils of DP980 with and without addition of boron which were industrially produced and also samples from annealing simulation. The analysis was based on properties from tensile test and microstructure. It was found that boron-added steel showed higher mechanical properties than no-boron steel, and this is due to higher martensite volume fraction of boron-added steel. This fact is related to boron segregation at ferrite / austenite interfaces during intercritical annealing, thereby avoiding the nucleation and growth of "new" ferrite, with a consequent enrichment of carbon in austenite. This enriched austenite promotes a higher volume fraction of martensite in the final microstructure. Thus, the boron-added steel industrially produced showed better microstructure and mechanical properties which are meeting with the requirements currently demanded of automotive industry, when hot-dip galvanized in the same process conditions used in this study.

Keywords: Boron; DP steels; Martensite.

1 Engenheiro de Desenvolvimento de Produtos, MSc, Gerência de Metalurgia, ArcelorMittal Vega, São Francisco do Sul, SC, Brasil.

2 Engenheiro de Desenvolvimento de Produtos, MSc, Gerência de Metalurgia, ArcelorMittal Tubarão, Serra, ES, Brasil.

3 Engenheiro de Desenvolvimento de Produtos, Gerência de Metalurgia, ArcelorMittal Vega, São Francisco do Sul, SC, Brasil.

\footnotetext{
* Contribuição técnica ao $51^{\circ}$ Seminário de Laminação - Processos e Produtos Laminados e Revestidos, 28 a 31 de outubro de 2014, Foz do Iguaçu, PR, Brasil.
} 


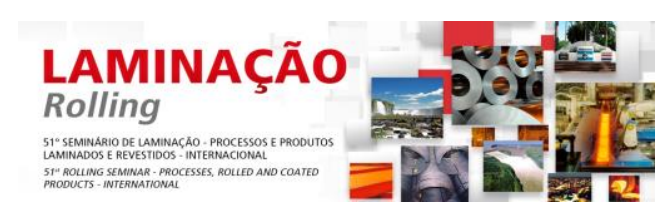

\section{INTRODUÇÃO}

O desenvolvimento de novos aços pela indústria siderúrgica tem sido impulsionado principalmente pelo setor automotivo, em função da busca incessante de projetar veículos mais leves e com melhor desempenho, mas sem perder em segurança veícular. Portanto, o desafio atual para as indústrias siderúrgicas é desenvolver aços com propriedades específicas que permitam a produção de componentes de menor espessura (menor peso), sem comprometer os requisitos restritos de segurança como os ensaios de "Crash Test" frontal e lateral.

Diante deste cenário, os aços AHSS (Advanced High Strength Steels) vêm para suprir a demanda atual da indústria automotiva, com atenção especial para os aços bifásicos (também chamados de Dual Phases), já que estes permitem atingir níveis de resistência que variam de 450 a $1200 \mathrm{MPa}$ juntamente com uma boa ductilidade, fazendo uso em diversas aplicações que vai desde a carroceria dos automóveis até rodas e peças estruturais. Esta combinação de propriedades mecânicas é consequência direta da sua microestrutura, que consiste basicamente em uma matriz ferrítica com ilhas de martensita, podendo ainda apresentar pequenas quantidades de perlita, bainita ou austenita retida [1].

Atualmente, os aços bifásicos são produzidos pela siderurgia mundial utilizando o processo de recozimento contínuo com aquecimento em temperaturas dentro da zona intercrítica, ou seja, entre as temperaturas $A_{1}$ e $A_{3}$. Vários estudos mostraram que as características mecânicas e microestruturais dos aços bifásicos são altamente influenciadas pelas variáveis de processo durante o recozimento intercrítico e pela composição química. Desta forma, a dificuldade na produção industrial dos aços bifásicos, principalmente aqueles com maior nível de resistência mecânica (> $980 \mathrm{MPa}$ ), está em conhecer e aliar a melhor condição de processo no tratamento térmico com a composição química ideal para a obtenção das propriedades mecânicas finais.

Por conseguinte, este estudo tem o objetivo de avaliar as propriedades mecânicas e microestruturais de um aço bifásico galvanizado a quente com resistência mínima de $980 \mathrm{MPa}$, com e sem adição do elemento químico boro. A partir destes resultados, espera-se padronizar uma rota metalúrgica para a produção comercial deste aço nas plantas da ArcelorMittal Brasil.

\subsection{Aços Bifásicos}

Em geral, as propriedades mecânicas de um aço bifásico são determinadas em função das frações volumétricas e das resistências da ferrita e martensita. A ferrita pode ser endurecida por solução sólida, por precipitação ou pelo refino de grão, e a resistência da martensita está diretamente associada ao teor de carbono desta fase. A combinação adequada das duas fases (ferrita e martensita) é o fator principal para atingir as propriedades mecânicas desejadas nos aços bifásicos. Se a fração volumétrica de martensita é baixa, haverá uma redução no limite de resistência e no coeficiente de encruamento, enquanto que o limite de escoamento poderá subir em função da existência de outros constituintes no lugar da martensita. Por outro lado, se a fração volumétrica de martensita é excessivamente alta, os limites de escoamento e resistência vão aumentar demasiadamente com uma consequente perda de ductilidade [2].

Vários autores estudaram a relação entre a fração volumétrica de martensita e o limite de resistência do aço bifásico. A figura 1 mostra esta relação para aços

* Contribuição técnica ao $51^{\circ}$ Seminário de Laminação - Processos e Produtos Laminados e Revestidos, 28 a 31 de outubro de 2014, Foz do Iguaçu, PR, Brasil. 


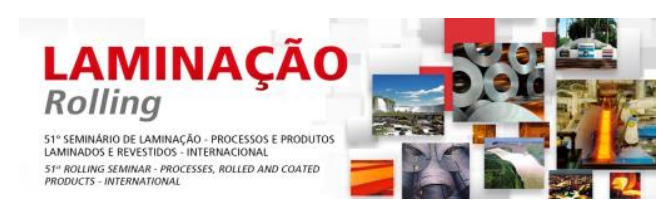

bifásicos com teores de carbono diferentes $(0,10 \%, 0,14 \%$ e $0,19 \%)$ recozidos intercriticamente [3].

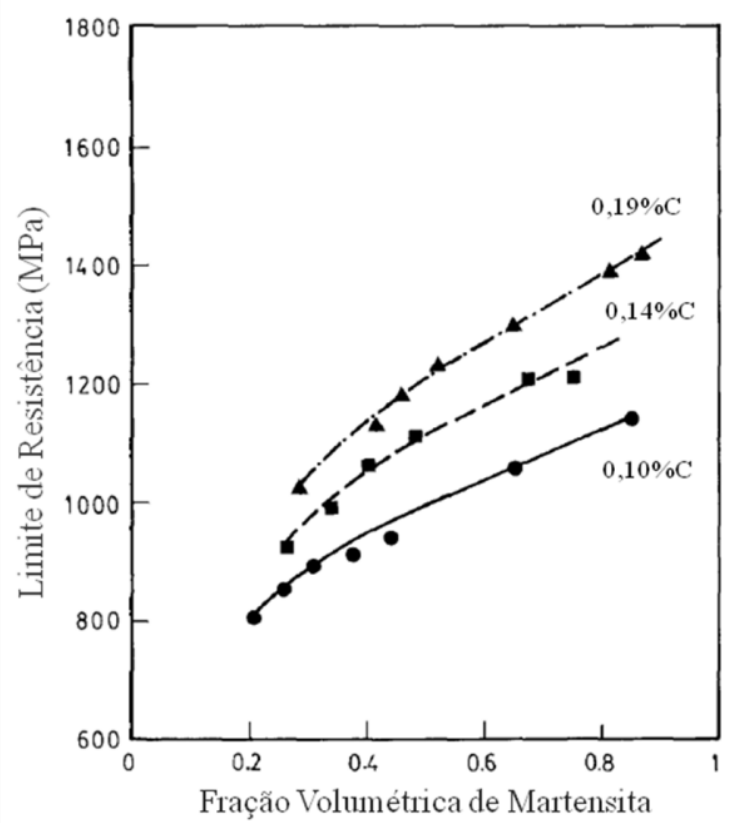

Figura 1. Efeito da fração volumétrica de martensita no limite de resistência de três aços [3].

bifásicos

O tamanho e a distribuição dos constituintes também têm efeito nas propriedades mecânicas dos aços bifásicos, especialmente na ductilidade. É desejável ter partículas pequenas e dispersas de martensita na matriz ferrítica, uma vez que, ilhas grosseiras e aglomeradas de martensita podem provocar um bandeamento desta fase funcionando como um caminho de fácil propagação de trincas, diminuindo assim a ductilidade do material.

Com relação ao processo de recozimento intercrítico dos aços bifásicos, as principais etapas são o aquecimento, o encharque e o resfriamento rápido. Inicialmente, o material é aquecido até a temperatura intercrítica e permanece durante um determinado tempo nesta temperatura (encharque). Nestes estágios, já ocorre a nucleação e o crescimento da austenita, formando então uma microestrutura mista de ferrita e austenita. Após o encharque, tem-se o resfriamento rápido com o objetivo de promover a transformação da austenita em martensita, formando então a microestrutura final desejada nos aços bifásicos de ferrita e martensita [4].

\subsection{Composição Química dos Aços Bifásicos}

A transformação da austenita durante o resfriamento está diretamente associada com a temperabilidade do aço bifásico e o carbono é o principal elemento que interfere nesta propriedade. Entretanto, outros elementos de liga como o manganês, cromo, molibdênio e boro também são adicionados para controlar esta temperabilidade e proporcionar uma "janela" de processo adequada aos atuais equipamentos das indústrias siderúrgicas.

A partir do momento que adiciona-se estes elementos de liga no aço, há uma alteração nas temperaturas de início e final de transformação da martensita, e

* Contribuição técnica ao $51^{\circ}$ Seminário de Laminação - Processos e Produtos Laminados e Revestidos, 28 a 31 de outubro de 2014, Foz do Iguaçu, PR, Brasil. 


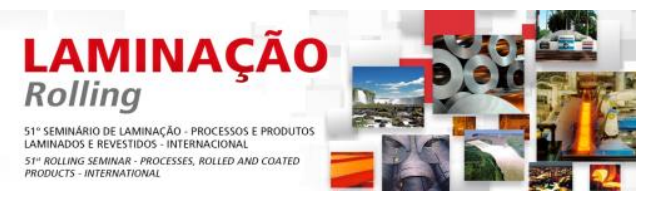

portanto, a composição química é fator predominante para a obtenção da microestrutura final desejada nos aços bifásicos (ferrita / martensita), bem como das suas propriedades mecânicas.

A soldabilidade também é uma importante propriedade requerida nos aços bifásicos uma vez que a maioria das peças da manufatura automotiva é soldada, e a composição química (especialmente o elemento químico carbono), tem grande influência nesta propriedade. Desta forma, houve ao longo dos últimos anos vários estudos para diminuir o teor de carbono total dos aços bifásicos, reduzindo consequentemente o seu carbono equivalente, a fim de melhorar a soldabilidade dos mesmos. Sendo assim, a adição de elementos microligantes também tem a função de compensar a perda de resistência do aço (provocada pela redução do teor de carbono), além de permitir um melhor controle das condições de processos termomecânicos necessários para atingir os requisitos de propriedades mecânicas finais.

A figura 2 mostra o efeito dos elementos químicos boro, molibdênio, cromo, vanádio e manganês na temperabilidade, expressa pela variação do limite de resistência do aço $(\Delta L R)$, em um aço base baixo carbono e manganês. Observa-se que o boro foi o elemento que mais afetou a temperabilidade, sendo que com apenas $10 \mathrm{ppm}$ de adição de boro houve um incremento de $82 \mathrm{MPa}$ no limite de resistência do aço. $\mathrm{O}$ molibdênio foi o segundo elemento que mais afetou a temperabilidade, sendo que houve um incremento de $67 \mathrm{MPa}$ para cada 0,1\% de adição de Mo [5].

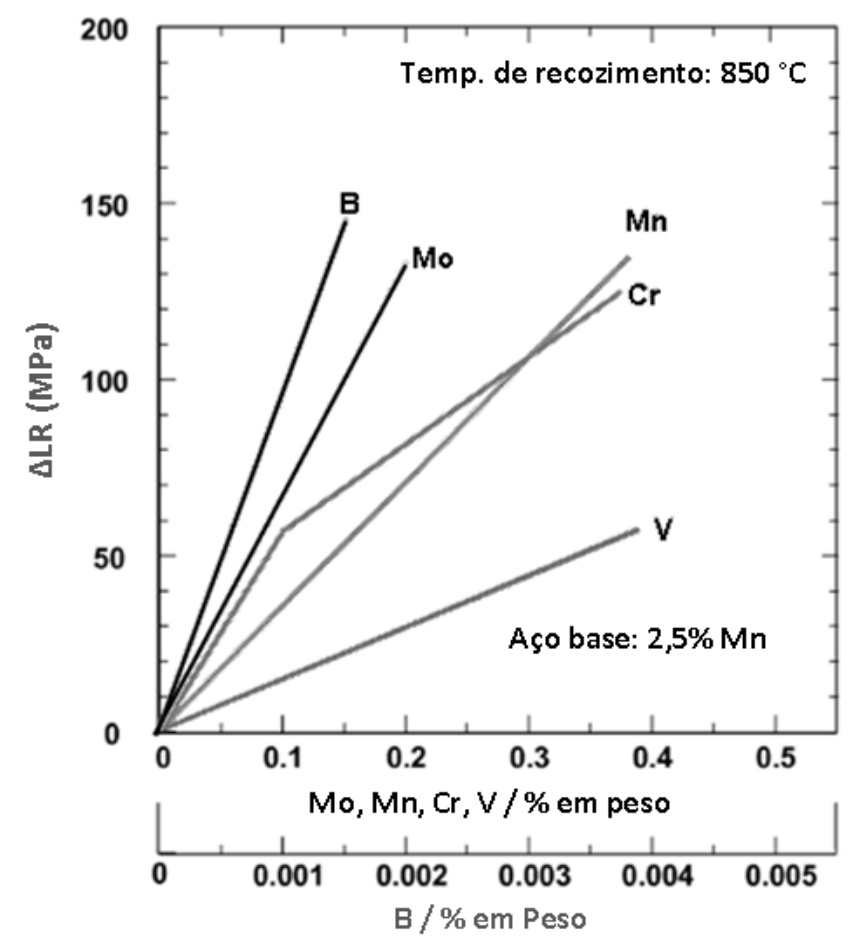

Figura 2. Efeito da adição de $B, M o, M n, C r$ e V na variação do limite de resistência do aço C-Mn [5].

O efeito do boro na temperabilidade dos aços está associado com a baixa solubilidade deste elemento na ferrita e austenita. Em função desta baixa solubilidade, o boro em solução sólida segrega nas interfaces $\alpha / \gamma$ durante 0 recozimento intercrítico, diminuindo a energia livre das interfaces e reduzindo desta forma a nucleação e crescimento da "nova" ferrita (ferrita proeutetóide) durante o resfriamento. Além disto, a segregação do boro nas interfaces $\alpha / \gamma$ inibe a

* Contribuição técnica ao $51^{\circ}$ Seminário de Laminação - Processos e Produtos Laminados e Revestidos, 28 a 31 de outubro de 2014, Foz do Iguaçu, PR, Brasil. 


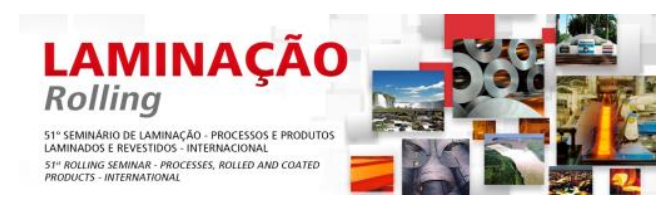

segregação do carbono nesta mesma região, liberando mais carbono para o enriquecimento da austenita. Este enriquecimento proporciona uma maior temperabilidade da austenita fazendo com que esta fase fique mais estável, gerando uma maior quantidade de martensita na microestrutura final [6,7].

A efetividade do boro na temperabilidade está relacionada com o teor de carbono do aço, uma vez que há uma competição entre a segregação destes dois elementos nos contornos de grãos austeníticos, podendo haver uma saturação dos sítios. Logo, o boro apresenta maior efetividade nos aços com baixo carbono.

\section{MATERIAIS E MÉTODOS}

Foram analisadas bobinas provenientes de duas corridas industriais de um aço bifásico baixo carbono ( 0,09\% C), com e sem adição de boro. Elementos como enxofre, fósforo, cobre e níquel estão presentes apenas em teores residuais. Estes aços serão referidos daqui em diante como DP s/ B e DP c/ B, conforme composição química mostrada na tabela 1.

Tabela 1. Composição química das corridas estudadas (\% em peso).

\begin{tabular}{ccccc}
\hline Aço & C & Mn & Mo & B \\
\hline DP s/ B & 0,09 & 2,3 & 0,18 & 0,0003 \\
DP c/ B & 0,09 & 2,3 & 0,18 & 0,0023 \\
\hline
\end{tabular}

Os processos de produção das corridas na aciaria e a laminação a quente (Upstream) foram realizados na ArcelorMittal Tubarão, localizada em Serra, ES, e os processos da laminação a frio, recozimento e galvanização (Downstream) foram realizados na ArcelorMittal Vega, localizada em São Francisco de Sul, SC.

A linha de galvanização a quente é composta por um forno de recozimento contínuo vertical com as seções de aquecimento, encharque, resfriamento e equalização, sendo que o tempo em cada uma destas seções está relacionado com a velocidade da linha. A figura 3 mostra o perfil do ciclo térmico para os aços bifásicos na linha de galvanização.

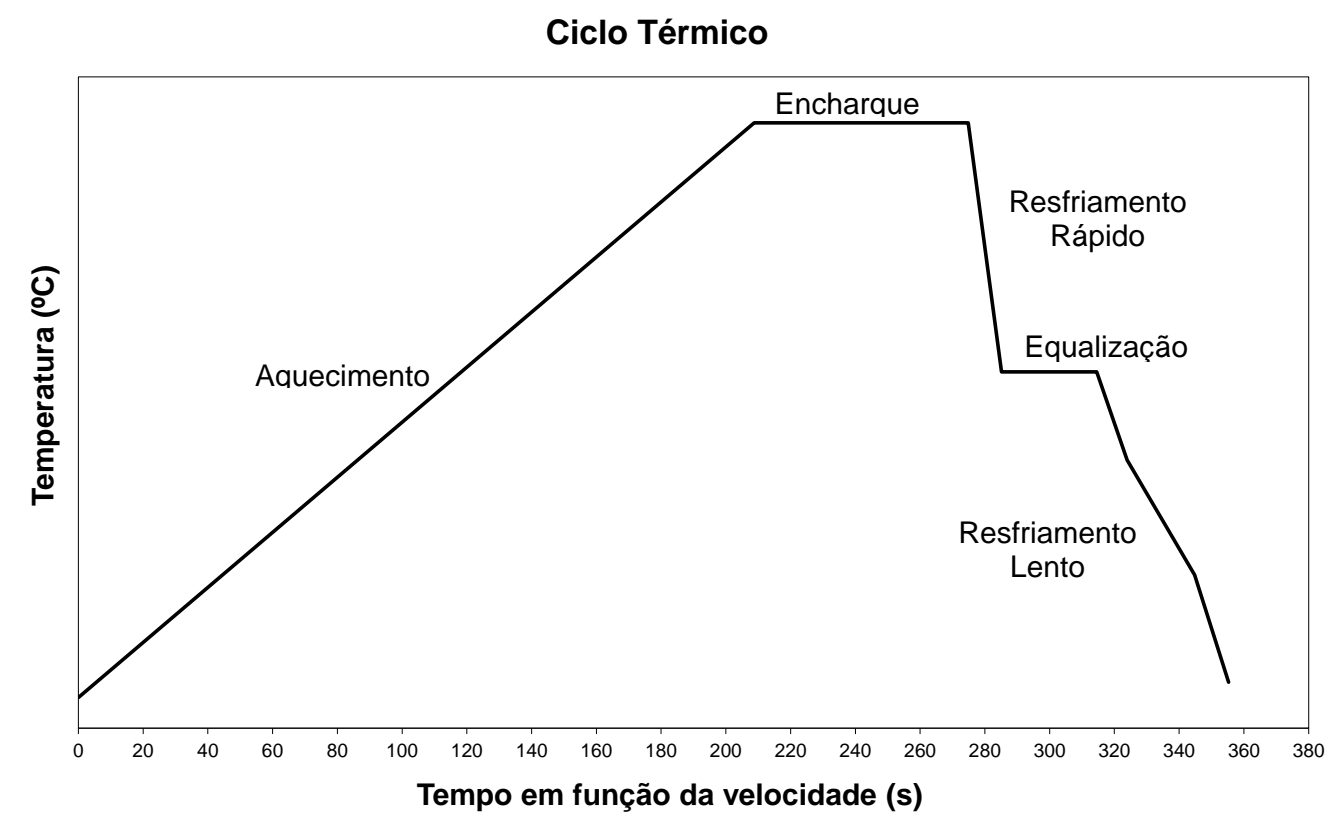

Figura 3. Perfil do ciclo térmico para os aços bifásicos

* Contribuição técnica ao $51^{\circ}$ Seminário de Laminação - Processos e Produtos Laminados e Revestidos, 28 a 31 de outubro de 2014, Foz do Iguaçu, PR, Brasil. 


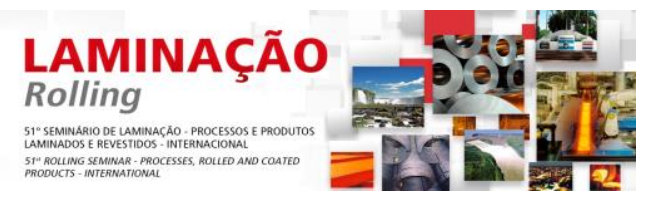

Antes da realização dos testes industriais na ArcelorMittal Vega, foram feitas simulações de tratamento térmico utilizando o equipamento CAS (Continuous Annealing Simulator), com o objetivo de encontrar a temperatura de recozimento intercrítico a ser visada na linha de galvanização a quente.

Com relação à caracterização mecânica, foram realizados ensaios de tração de acordo com a norma DIN-EN 10002 em um máquina universal de ensaios, sendo que os corpos de prova foram retirados no sentido longitudinal à direção de laminação.

A caracterização microestrutural foi feita através de microscópia eletrônica de varredura (MEV). Todas as amostras foram cortadas no sentido de laminação, embutidas, lixadas, polidas e atacadas com o reativo nital, de modo a revelar as fases e contornos de grãos. As frações volumétricas de martensita foram calculadas através do método manual de contagem de área, utilizando uma grade de 920 pontos $(40 \times 23)$. Foram realizadas três medições em cada uma das amostras deste estudo, sendo que para a análise dos resultados, foi considerada a média das três medidas.

\section{RESULTADOS E DISCUSSÃO DOS RESULTADOS}

\subsection{Produção Industrial (Bobina Laminada a Quente)}

Para a produção industrial do aço bifásico DP980 na ArcelorMitta Tubarão, destacase a utilização de desgaseificadores à vácuo na aciaria (limpidez), o uso do lingotamento contínuo e um controle rigoroso nos parâmetros metalúrgicos de laminação a quente.

As placas dos dois aços foram produzidas com boa qualidade interna e com a ausência de trincas térmicas superficiais avaliadas via "macroetch" (teste de Baumann), conforme pode ser visto na figura 4.

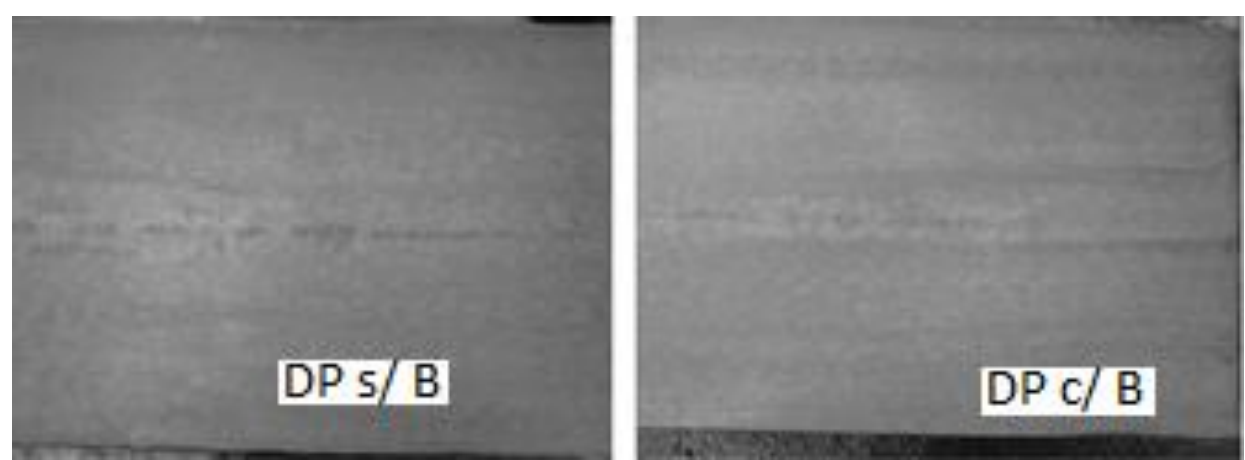

Figura 4. Resultados do ensaio de Baumann nas placas de DP980 com e sem boro.

O controle das temperaturas de acabamento e bobinamento associado a uma estratégia de resfriamento adequada no laminador de tiras a quente permite a obtenção de uma bobina laminada a quente com microestrutura inicial apropriada. Para aços bifásicos com menor resistência mecânica, tem-se uma microestrutura inicial composta de ferrita e perlita. Para aços bifásicos com maior resistência mecânica (DP980, DP1180), tem-se como origem uma microestrutura inicial mais complexa, uma vez que, neste caso, são necessários mais sítios de nucleação da austenita, e tanto os carbonetos como as fases que contém carbono (bainita e martensita) funcionam como pontos de nucleação durante 0 processo de austenitização [8].

* Contribuição técnica ao $51^{\circ}$ Seminário de Laminação - Processos e Produtos Laminados e Revestidos, 28 a 31 de outubro de 2014, Foz do lguaçu, PR, Brasil. 


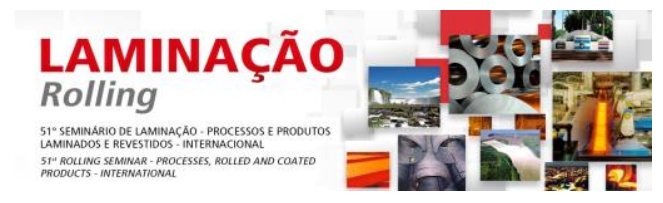

A tabela 2 apresenta os resultados de propriedades mecânicas das bobinas laminadas a quente do aço DP980 com e sem adição de boro. Os resultados mostraram um incremento na resistência mecânica no aço DP c/ B (aumento no limite de escoamento e no limite de resistência em 86 e $82 \mathrm{MPa}$, respectivamente) enquanto o alongamento total apresentou uma queda de $4,5 \%$.

Tabela 2. Propriedades mecânicas do aço laminado a quente DP980 com e sem adição de boro.

\begin{tabular}{ccccc}
\multirow{2}{*}{ Aço } & - & $\begin{array}{c}\mathrm{LE} \\
(\mathrm{MPa})\end{array}$ & $\begin{array}{c}\text { LR } \\
(\mathrm{MPa})\end{array}$ & $\begin{array}{c}\text { ALO } \\
(\%)\end{array}$ \\
\hline \multirow{2}{*}{ DP s/ B } & Média & 673 & 981 & 12 \\
& Desvio Padrão & 38 & 36 & 1 \\
\multirow{2}{*}{ DP c/ B } & Média & 759 & 1063 & 7,5 \\
& Desvio Padrão & 23 & 14 & 2 \\
\hline
\end{tabular}

A figura 5 mostra as microestruturas do aço DP980 com e sem adição de boro, como laminado a quente. Observa-se uma maior fração volumétrica de martensita e bainita no aço com boro, sendo que este aço apresentou uma somatória destes constituintes de $34 \%$ enquanto o aço sem adição de boro apresentou uma somatória de $18 \%$.

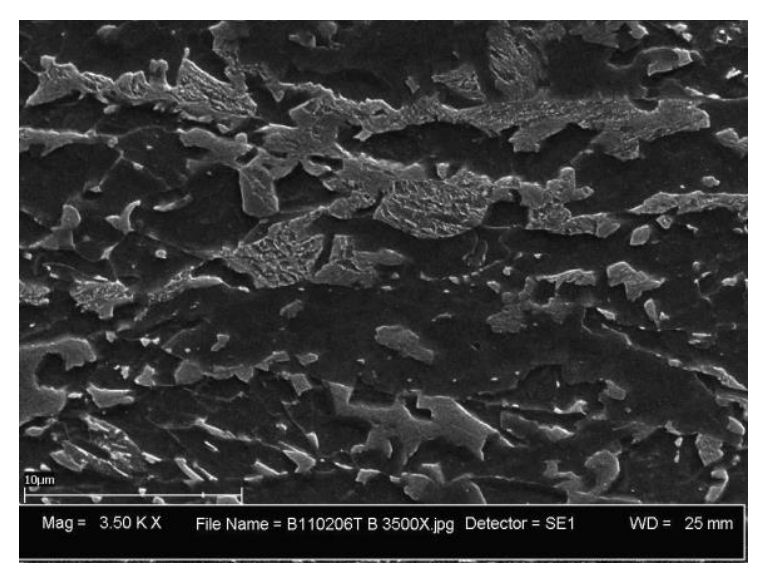

DP s/ B laminado a quente

Microestrutura constituída por Ferrita e Martensita + Bainita $=18 \%$

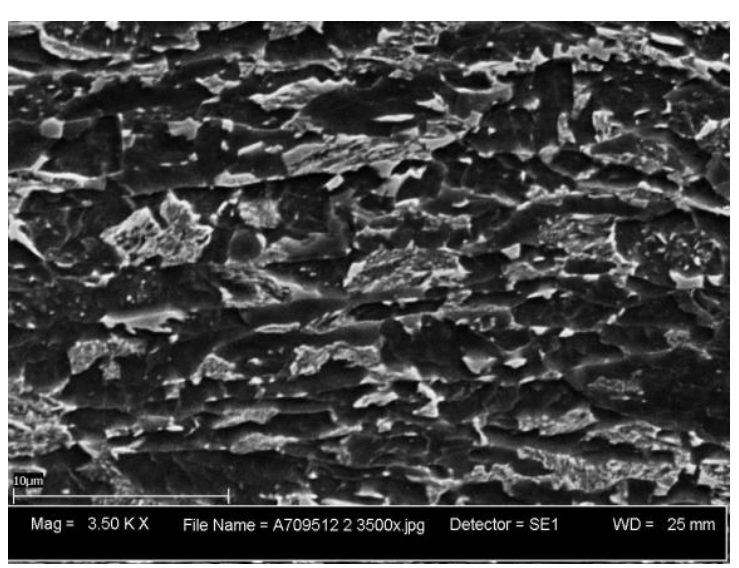

DP c/ B laminado a quente

Microestrutura constituída por Ferrita e Martensita + Bainita: $34 \%$

Figura 5. Microestruturas do aço DP com e sem adição de boro, como laminado a quente. MEV, ataque nital $2 \%$.

\subsection{Simulação do Ciclo Térmico}

Visando encontrar a temperatura ideal de tratamento térmico a ser aplicada na galvanização, foi realizada uma simulação de recozimento na corrida com adição de boro usando temperaturas entre 760 e $840 \stackrel{\circ}{\circ}$. A figura 6 mostra os resultados de limite de escoamento, limite de resistência e fração volumétrica de martensita das amostras recozidas, em função da temperatura de recozimento.

* Contribuição técnica ao $51^{\circ}$ Seminário de Laminação - Processos e Produtos Laminados e Revestidos, 28 a 31 de outubro de 2014, Foz do Iguaçu, PR, Brasil. 

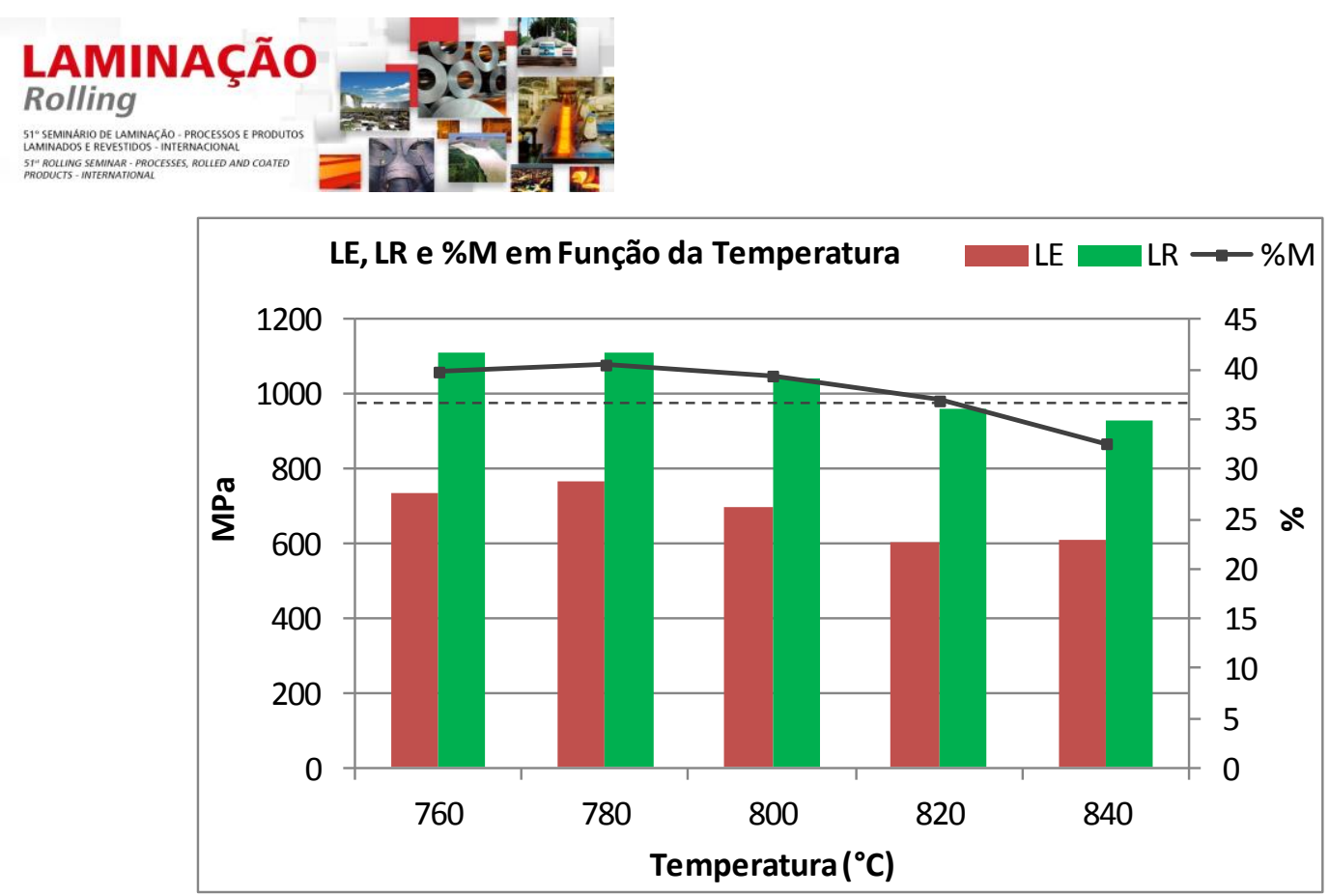

Figura 6. LE, LR e fração volumétrica de martensita em função da temperatura de recozimento.

Observou-se uma queda acentuada nas propriedades mecânicas e na fração volumétrica de martensita para temperaturas acima de $800^{\circ} \mathrm{C}$, gerando valores de limite de resistência abaixo do específicado para o aço bifásico DP980 (LR mínimo de $980 \mathrm{MPa}$ ). Este fato pode ser explicado pela quantidade e temperabilidade da austenita a altas temperaturas. À medida que a temperatura intercrítica aumenta, há um aumento da fração volumétrica de austenita, e consequentemente, há uma diminuição do teor médio de carbono desta fase, diminuindo assim a sua temperabilidade. Esta baixa temperabilidade facilita a formação de outras fases além da martensita durante o resfriamento, como por exemplo, a formação da bainita e da "nova" ferrita (ferrita proeutetóide).

Além da baixa fração volumétrica de martensita, a granulação mais grosseira a altas temperaturas também contribuiu para a redução do limite de escoamento e limite de resistência do material. A figura 7 mostra as microestruturas obtidas a 760 e $840^{\circ} \mathrm{C}$, onde é possível observar a ocorrência de bainita na microestrutura de maior temperatura, bem como um maior tamanho de grão ferrítico e maiores ilhas de martensita.
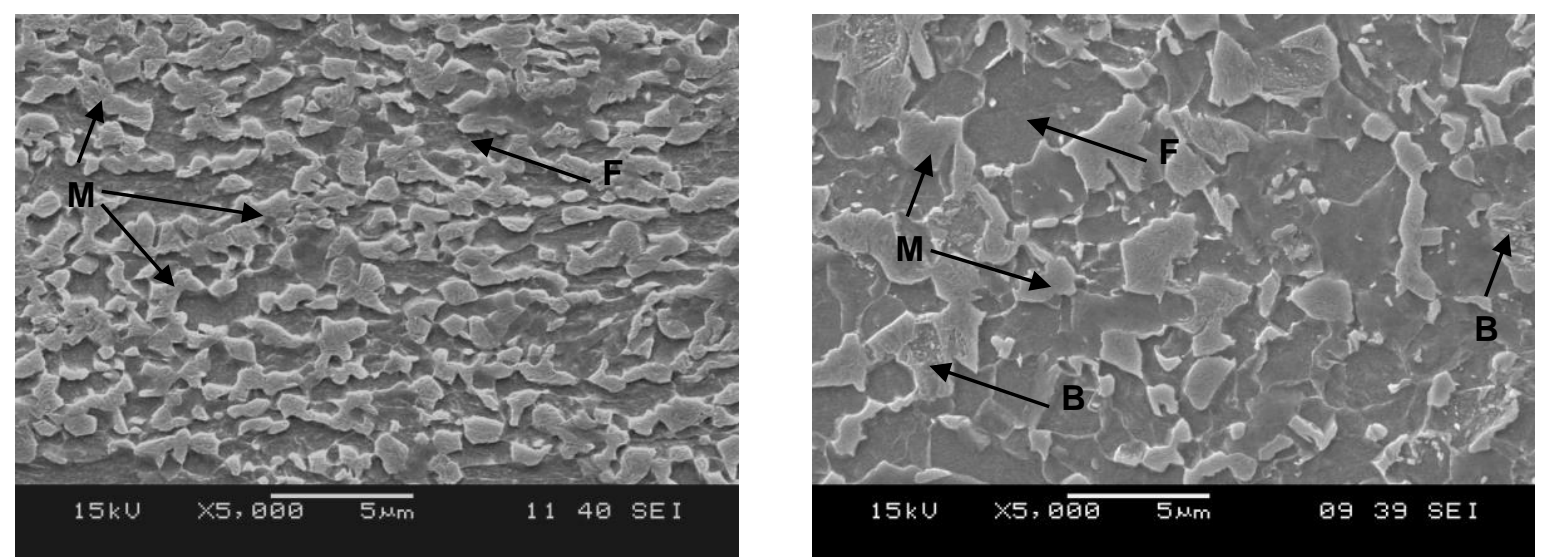

Figura 7. Microestruturas recozidas a 760 e $840^{\circ} \mathrm{C}$ (indicação da ferrita, martensita e bainita). MEV, ataque nital $4 \%$.

Os resultados da simulação mostraram uma boa combinação de propriedades mecânicas e microestrutura entre as temperaturas de 760 e $800^{\circ} \mathrm{C}$, e diante disso,

* Contribuição técnica ao $51^{\circ}$ Seminário de Laminação - Processos e Produtos Laminados e Revestidos, 28 a 31 de outubro de 2014, Foz do Iguaçu, PR, Brasil. 


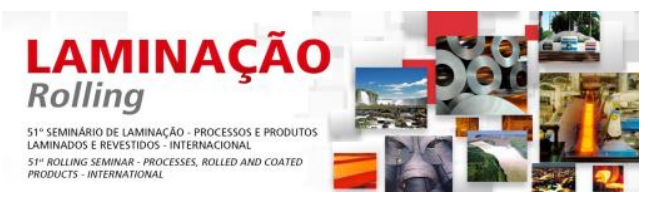

foi definida a temperatura de recozimento de $790^{\circ} \mathrm{C}$ a ser visada na galvanização durante a produção industrial.

\subsection{Produção Industrial (Bobina Galvanizada a Quente)}

As bobinas provenientes das corridas de DP980 com e sem adição de boro foram processadas na linha de galvanização com uma temperatura de recozimento de $790^{\circ} \mathrm{C}$ com $\pm 10^{\circ} \mathrm{C}$. A tabela 3 mostra os resultados de limite de escoamento (LE), limite de resistência (LR), alongamento total (ALO) e coeficiente de encruamento (valor $n$ ) das bobinas como galvanizada a quente, bem como a faixa especificada pela indústria automotiva.

Tabela 3. Propriedades mecânicas do aço DP980 com e sem adição de boro.

\begin{tabular}{cccccc}
\hline \multirow{2}{*}{ Aço } & - & $\begin{array}{c}\text { LE } \\
(\mathrm{MPa})\end{array}$ & $\begin{array}{c}\text { LR } \\
(\mathrm{MPa})\end{array}$ & $\begin{array}{c}\text { ALO } \\
(\%)\end{array}$ & $\begin{array}{c}\text { Valor } \\
\mathrm{n}\end{array}$ \\
\hline \multirow{2}{*}{ DP s/ B } & Média & 669 & 960 & 15 & 0,173 \\
& Desvio Padrão & 35 & 31 & 1 & 0,023 \\
\multirow{2}{*}{ DP c/ B } & Média & 699 & 1025 & 14 & 0,160 \\
& Desvio Padrão & 37 & 31 & 1 & 0,023 \\
\hline \multirow{2}{*}{ Especificação } & $600-$ & $\geq 980$ & $\geq 10$ & $\geq 0,08$ \\
\hline
\end{tabular}

Os resultados da tabela acima mostraram um aumento da resistência mecânica no aço bifásico com adição de boro, através do aumento no limite de escoamento e no limite de resistência, em $30 \mathrm{MPa}$ e $65 \mathrm{MPa}$, respectivamente. As propriedades de alongamento total e valor $\mathrm{n}$ foram coerentes com este aumento de resistência, ou seja, o aço com adição de boro apresentou menores valores de ALO e $n$, o que reflete uma pequena perda de estampabilidade neste aço.

A análise microestrutural mostrou uma maior fração volumétrica de martensita no aço com boro, sendo que este aço apresentou uma fração média desta fase de $48 \%$ e o aço sem adição de boro apresentou uma fração média de $41 \%$. A figura 8 mostra as microestruturas dos aços DP980 com e sem adição de boro, analisadas no microscópio eletrônico de varredura (MEV) com ataque nital a 4\%. Observa-se que em ambos os aços, há uma microestrutura composta basicamente de ferrita e martensita.

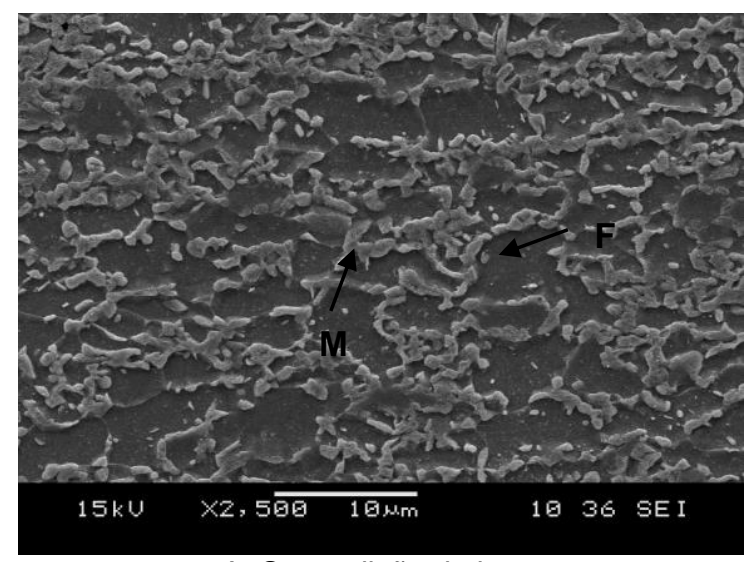

A: Sem adição de boro

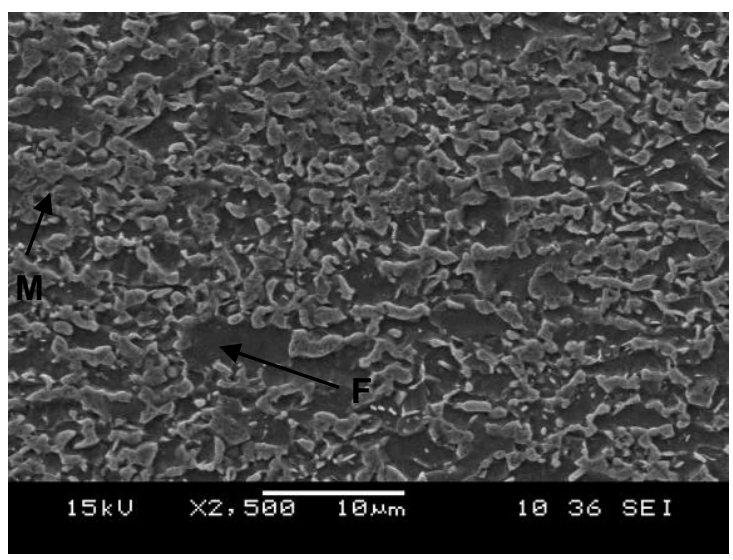

B: Com adição de boro

Figura 8. Microestruturas do aço bifásico DP980 com e sem adição de boro. MEV, ataque nital 4\%.

* Contribuição técnica ao $51^{\circ}$ Seminário de Laminação - Processos e Produtos Laminados e Revestidos, 28 a 31 de outubro de 2014, Foz do Iguaçu, PR, Brasil. 


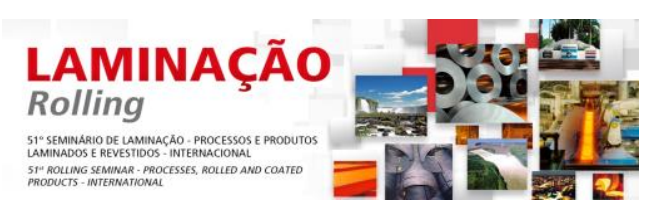

A comparação entre as microestruturas dos dois aços confirmam o efeito do boro na maior geração da martensita durante o resfriamento, através da segregação deste elemento nas interfaces ferrita / austenita no recozimento intercrítico. Conforme comentado anteriormente, esta segregação diminui a energia livre das interfaces reduzindo a nucleação e crescimento da "nova" ferrita, e além disso, há uma maior liberação de carbono para o enriquecimento da austenita com a conseqüente transformação desta fase em martensita [9].

Conforme pode se visto na figura 9, a maior fração volumétrica de martensita no aço com adição de boro pode explicar a diferença entre o limite de resistência dos dois aços estudados, uma vez que esta propriedade é diretamente influenciada por este constituinte. À medida que aumenta a fração volumétrica de martensita, há um aumento nas propriedades de limite de escoamento e limite de resistência dos aços bifásicos [3].

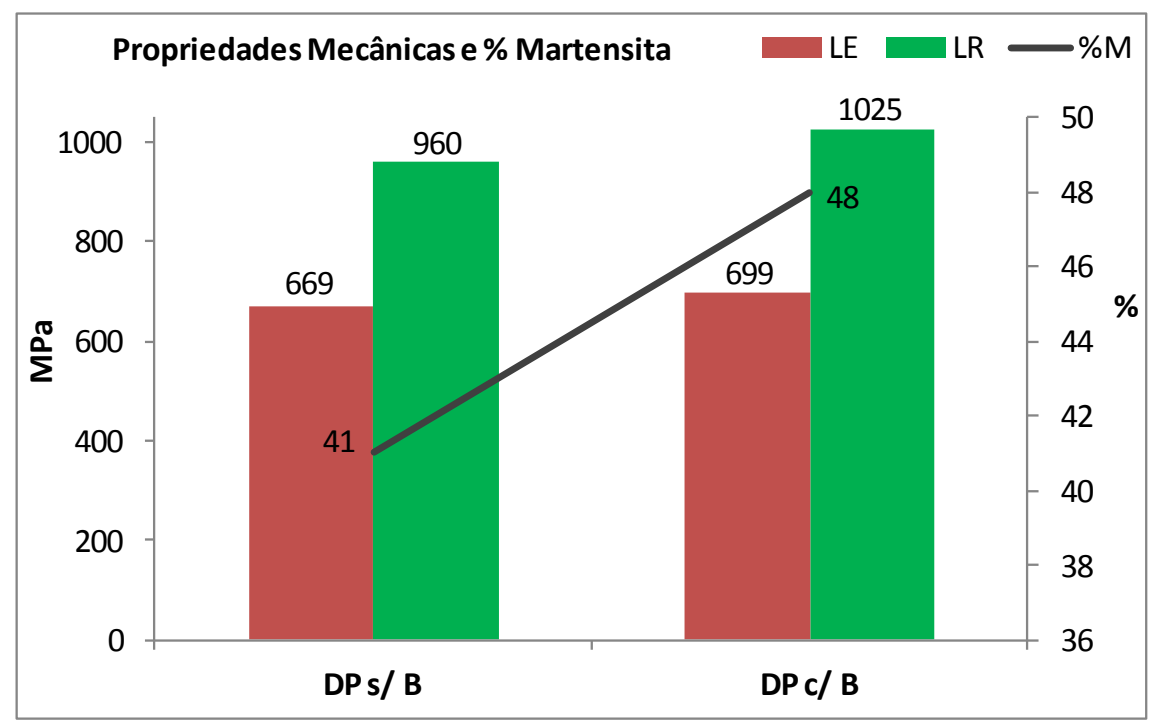

Figura 9. Propriedades mecânicas e fração volumétrica de martensita dos dois aços estudados.

Os resultados de propriedades mecânicas obtidos mostraram uma boa concordância com a temperatura de recozimento aplicada. Sabe-se que a temperatura tem influência direta na quantidade de austenita formada e no teor de carbono desta fase, e conseqüentemente, na fração volumétrica de martensita gerada [10,11]. Usando a temperatura de $790^{\circ} \mathrm{C}$ juntamente com a velocidade regular de processo na linha de galvanização, foi possível obervar através das microestruturas que houve uma boa combinação entre a porcentagem de austenita formada e a taxa de resfriamento aplicada, evitando desta forma a formação de outros constituintes como por exemplo a perlita e a bainita, e promovendo assim, a fração volumétrica ideal de martensita na microestrutura final.

Tanto nas microestruturas do aço laminado a quente como no aço galvanizado (figuras 5 e 8 respectivamente), é possível obervar que o boro provocou um refinamento na microesrutura. Portanto, podemos afirmar que o menor valor de resistência mecânica no aço sem a adição de boro também está associado com a formação de um grão ferrítico mais grosseiro e ilhas maiores de martensita neste material.

Com relação ao atendimento das propriedades mecânicas requeridas pela indústria automotiva (tabela 3), pode-se afirmar que o aço com adição de boro produzido industrialmente como galvanizado a quente atendeu plenamente estes requisitos. $\mathrm{O}$

* Contribuição técnica ao $51^{\circ}$ Seminário de Laminação - Processos e Produtos Laminados e Revestidos, 28 a 31 de outubro de 2014, Foz do Iguaçu, PR, Brasil. 


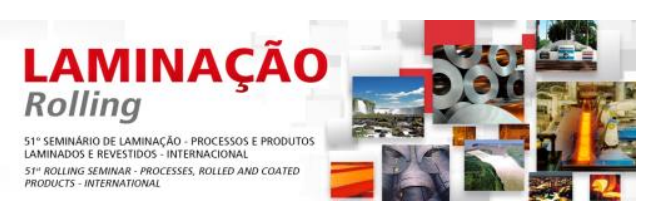

mesmo não aconteceu para o aço sem a adição deste elemento, pois neste caso, o limite de resistência ficou abaixo do especificado.

\section{CONCLUSÃO}

- A adição de boro no aço bifásico como laminado a quente teve efeito significativo nos valores de propriedades mecânicas (LE, LR e ALO) e na microestrutura (fração de bainita e martensita).

- A produção industrial do aço bifásico na linha de galvanização foi coerente com os resultados obtidos por simulação, mostrando que a janela de temperatura proposta de $790 \pm 10^{\circ} \mathrm{C}$ é uma boa referência para as próximas produções.

- O aço bifásico com adição de boro apresentou propriedades mecânicas mais elevadas que o aço sem a adição deste elemento, com uma diferença de $30 \mathrm{MPa}$ para o limite de escoamento e $65 \mathrm{MPa}$ para o limite de resistência.

- O aço bifásico com adição de boro apresentou maior fração volumétrica de martensita que o aço bifásico sem a adição deste elemento. Esta diferença está relacionada à capacidade do boro em segregar nas interfaces ferrita / austenita durante o recozimento, diminuindo a energia nestas interfaces e evitando a nucleação e crescimento da "nova" ferrita, e por conseguinte, há o enriquecimento de carbono na austenita.

- A maior fração volumétrica de martensita no aço bifásico com adição de boro explica as propriedades mecânicas mais elevadas neste aço, uma vez que há a correlação forte entre este consituinte e o limite de resistência.

- Com relação ao atendimento das propriedades mecânicas requeridas, o aço bifásico com adição de boro produzido industrialmente atendeu plenamente estes requisitos, diferente do aço sem a adição deste elemento.

\section{Agradecimentos}

Os autores agradecem a ArcelorMittal pela oportunidade.

\section{REFERÊNCIAS}

1 Priestner R, Ajmal M. Effect of Carbon Content and Microalloying on Martensitic Hardenability of Austenite of Dual-Phase Steel. Materials Science and Technology, 1987; 3: 360-364.

2 Lanzillotto CAN, Pickering FB. Structure-Property Relationships in Dual-Phase Steels. Metal Science, 1982; 16: 371-382.

3 Chen HC, Cheng GH. Effect of Martensite Strength on the Tensile Strength of Dual Phase Steels. Journal of Materials Science, 1989; 24: 1991-1994.

4 Mohanty RR, Girina OA, Fonstein NM. Effect of Heating Rate on the Austenite Formation in Low-Carbon High-Strength Steels Annealed in the Intercritical Region. Metallurgical and Materials Transactions A, 2011; 42A: 3680-3690.

5 Iwama T, Kitano F, Nagataki Y, Matsuda H, Tanaka Y, Hosoya Y. Development of Galvannealed Dual-Phase Ultra-High Strength Steel Sheets with Superior Formability and Spot-Weldability. Galvatech'04 Conference Proceedings, p. 539-545, April 2004.

6 Shen XP, Priestner R. Effect of Boron on the Microstructure and Tensile Properties of Dual-Phase Steel. Metallurgical Transactions A, 1990; 21A: 2547-2553.

7 Totten GE. Steel Heat Treatment - Metallurgy and Technologies. Taylor \& Francis Group, Portland, 2nd Edition, p. 177-195, 2006.

8 Speich GR. Physical Metallurgy of Dual-Phase Steels. Fundamentals of Dual Phase Steels. The Metallurgical Society of AIME, Chicago, p. 3-45, February 1981.

* Contribuição técnica ao $51^{\circ}$ Seminário de Laminação - Processos e Produtos Laminados e Revestidos, 28 a 31 de outubro de 2014, Foz do Iguaçu, PR, Brasil. 


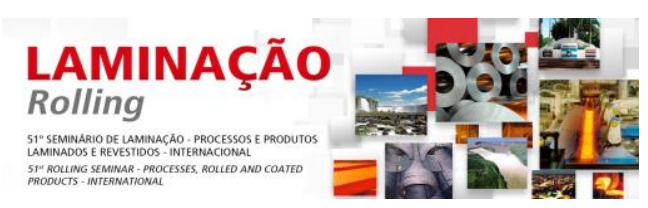

9 Suski CA, Oliveira CAS. Effect of Austenitization Temperature on the Precipitation of Carbides in Quenched Low Carbon Boron Steel. Metallography, Microstructure and Analysis, 2013; 2: 79-87.

10 Huang J, Poole WJ, Militzer M. Austenite Formation during Intercritical Annealing. Metallurgical and Materials Transactions A, 20004; 35A: 3363-3375.

11 Erdogan M. Effect of Austenite Dispersion on Phase Transformation in Dual Phase Steel. Scripta Materialia, 2003; 48: 501-506.

* Contribuição técnica ao $51^{\circ}$ Seminário de Laminação - Processos e Produtos Laminados e Revestidos, 28 a 31 de outubro de 2014, Foz do Iguaçu, PR, Brasil. 